\title{
Typological diversity of tall buildings and complexes in relation to their functional structure
}

\author{
Viktor P. Generalov ${ }^{1 *}$, Elena M. Generalova ${ }^{1}$, Nadezhda A. Kalinkina ${ }^{1}$ and Irina V. \\ Zhdanova \\ ${ }^{1}$ Samara State Technical University, 443001, Samara, Molodogvardeyskaya St, 194, Russia
}

\begin{abstract}
The paper focuses on peculiarities of tall buildings and complexes, their typology and its formation in relation to their functional structure. The research is based on the analysis of tall buildings and complexes and identifies the following main functional elements of their formation: residential, administrative (office), hotel elements. The paper also considers the following services as «disseminated» in the spaceplanning structure: shops, medicine, entertainment, kids and sports facilities, etc., their location in the structure of the total bulk of the building and their impact on typological diversity. Research results include suggestions to add such concepts as «single-function tall buildings» and «mixed-use tall buildings and complexes» into the classification of tall buildings. In addition, if a single-function building or complex performs serving functions, it is proposed to add such concepts as «a residential tall building (complex) with provision of services», «an administrative (public) tall building (complex) with provision of services» into the classification of tall buildings. For mixed-use buildings and complexes the following terms are suggested: «a mixed-use tall building with provision of services», «a mixed-use tall complex with provision of services».
\end{abstract}

\section{Introduction}

There is a process of intensive construction of tall buildings as well as a tendency to strengthen research, design, construction bases and to increase investment in this area of industry in some countries.

The concept of «sustainable development of vertical urbanism», which is closely connected with the search for new types of tall buildings, is also being developed. Tall buildings, that are rising up, are a particular social and economic indicator of progress, of the prestige of cities, firms, the political power of the state [1]. Besides, implementation of tall buildings developments leads to efficient use of urban land, reduced traffic flow, easy access to points of attraction for residents of cities, to creating so-called «compact cities». World experience of embedding tall buildings and complexes in the urban development shows a positive shift in terms of increasing the level of comfort, creating a modern

*Corresponding author: vp_generalov@mail.ru 
comfortable residential environment not only for inhabitants of skyscrapers, but also for the population in general. As new tall buildings appear and this trend in construction goes on and develops, there is also a debate about their typological diversity. Thus, there is a need for further study, research and systematization of these unique typological constructions [211]. Functional-typological characteristics of tall buildings and complexes have their own specific features, which are closely connected with the space-planning structure of tall buildings or complexes.

Currently, both domestic and foreign regulatory framework for the design and construction of tall buildings does not give clear recommendations concerning typological diversity of tall buildings. There is no classification of their types, either. The only exception is the international standards for measuring and defining tall buildings, which were developed by the Council on Tall Buildings and Urban Habitat (CTBUH). In accordance with this standard, buildings above $100 \mathrm{~m}$ high are recognized as tall buildings. In Russia, tall buildings are those which are at least $75 \mathrm{~m}$ high. When buildings with a height of 300 meters and higher appeared, CTBUH suggested additions to the standards for defining tall buildings. Thus, buildings of 300 to 600 meters are recognized as Supertall skyscrapers, and those over 600 meters - as Megatall skyscrapers. According to the latest data, more than 250 tall buildings will have a height of over 300 meters by 2020 , and there will be 8 buildings over 600 meters. As of today, there are only 3 megatalls completed globally. They are «Burj Khalifa» in Dubai, 828 meters high, «Shanghai Tower» in Shanghai, which is 632 meters and «Makkah Clock Royal Tower» in Mecca, which is 601 meters.

\section{Methods}

It should be noted that there is a certain clarity as far as the height of buildings is concerned. As to their functional structure, there is no regulation or complete research yet. At the same time, the nature and character of regulatory requirements for the design, construction and operation of a building are determined by characteristics of functional elements of the building. When analyzing the existing normative foreign and domestic regulations of tall buildings construction, it is difficult to find clear recommendations on typological features of tall buildings in relation to their functional purpose. Now, three main functional types of tall buildings are mentioned: residential, office and mixed-use tall buildings. The analysis of skyscrapers built in different countries reveals that they hold such main functional elements as residential, administrative (office), hotel elements. These features form and define the type of a tall building by its functional use. In domestic typology they can be divided into three main types: residential, public (administrative, office, hotel) and of mixed use.

In addition, in practice there are various «blotches» and «blendings» of main functional elements in a single space-planning decision. E.g. there might be offices or hotel rooms in residential buildings. At the same time, there might be a certain percentage of residential apartments in an office building. Which building can be considered to be a single-function residential or public (office) building, and which can be referred to as a mixed-use building? Apart from that, there are service functions which may be (and may be not) included in their space-planning structure.

To introduce an adequate, user-friendly regulatory framework, it is necessary to create a clear tall buildings subdivision into types depending on their functional properties. Such a subdivision would solve many challenges in the design, construction and operation of tall buildings. Sad to say, there is no clarification of concepts such as «a single-function building» and «a mixed-use building or complex» in existing regulatory documents. 
E.g., SP 160.1325800.2014 «Mixed-use buildings and complexes. Design rules» gives definitions to a mixed-use building and a mixed-use complex. But the interpretation which is given in this document is not, in our view, quite accurate and raises several questions. According to his document, a mixed-use building is a building in which two or more functionally-planning components are interconnected by using planning techniques. A definition of a mixed-use complex is not accurate, either. It says that such a complex holds two or more buildings for different functional purposes, which may be of mixed use and interconnected by planning techniques. It is clear, that this definition of multi-functionality of the building lacks clarity. Besides, this set of rules is designed only for the design, construction and operation of buildings and complexes up to a height of 75 meters with the allowed location of public spaces not higher than 55 meters. At the same time, SP 267.1325800.2016 «Tall buildings and complexes. Design rules» does not even mention tall buildings and complexes, as well as their functional-typological structure.

\section{Results}

Let us study foreign literature to find a solution to this problem. It should be noted that in foreign literature this issue is examined more clearly and thoroughly. As for the definitions of «single» and «mixed use» tall buildings, there are clear recommendations given. To «single-function» buildings they attribute buildings in which $85 \%$ or more of the total area is used for a basic function (residential, administrative, or office, hotel, etc.). To «mixeduse» buildings they refer buildings in which two or more functions are combined. The share of these functions here should be more than $15 \%$ of the total area of the building.

This classification of single and mixed-use buildings, in our opinion, could easily be fitted into the Russian Classification of functional characteristics of tall buildings. This would provide a basic framework for a general classification of tall buildings and complexes by their functional use. But, as we noted earlier, apart from the main functional constitutive elements, there are also functions for infrastructure maintenance and service provision implemented in these buildings structure. They are shopping, medical, library, sports and physical training facilities, institutions, cultural establishments, etc. It is a modern approach to the formation of living environment to provide services implemented into the building structure. According to their space-planning structure, these elements can be either embedded into a tall building or attached to it. Our analysis of existing buildings and complexes revealed that embedded-or-attached elements (as a base part of the building or complex) are the most common elements at the moment.

To what type of buildings should we refer a tall building, which performs a dominating function of residential or office use but also provides a service function? The same question relates to mixed-use buildings or complexes. The main purpose of including service functions into the structure of a building or complex is to create a comfortable, modern, high-quality living environment for human habitation. The number of serving functional elements and their intensity is not taken into account in this case, but they directly affect qualitative characteristics of a living environment in a tall building or complex. The only criterion to be taken into account when determining such types of buildings is the accessibility to elements of service and infrastructure facilities and convenience of their use by people regardless of time of day, year, weather conditions, etc.

\section{Discussion}

Summing up the results of the study, the authors propose creating a typological range of this type of buildings and complexes. Thus, it seems appropriate to determine that «a 
single-function building (complex)» is a building (complex), in which the main function covers $85 \%$ or more of the total area of this tall building (complex), and other functions (residential, office, hotel), interconnected by planning techniques, cover $15 \%$ or less of this building area. Besides, this «single-function building or building complex» can be a building with provision of services. In real life, there exist single-function buildings either with provision of services or without them. Depending on the basic functional element in the structure of a tall building, a single-function tall building with provision of services can be either «a residential tall building with provision of services» or «a public (office) tall building with provision of services».

If an architectural structure consists of two or more tall buildings performing one function it is recognized as «a tall single-function complex». If this structure holds service functions, it is «a single-function complex with provision of services». For example, the main function of the building is residential. Thus, this is a residential tall complex with provision of services.

To «mixed-use buildings» we refer buildings in which additional functions cover more than $15 \%$ of the total area of the building, and the dominating function covers less than $85 \%$ of the total area of the building. If the structure of a building or complex provide service functions, it is a mixed-use building or complex. It can be either «a mixed-use tall building with provision of services», «a mixed-use tall complex with provision of services».
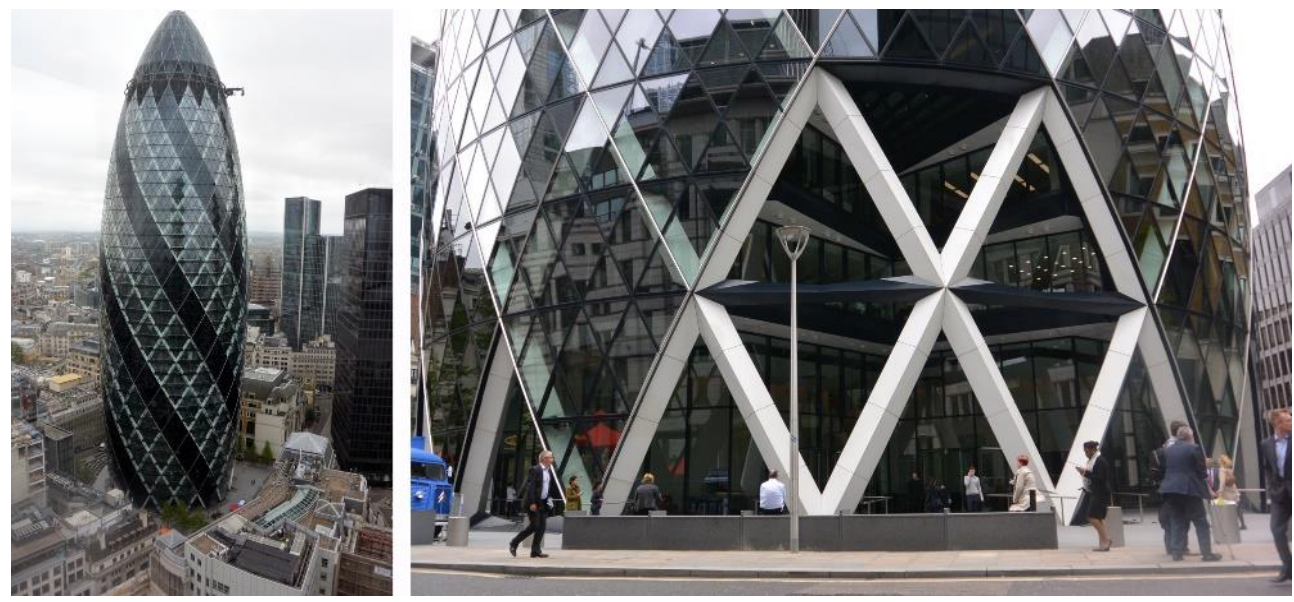

Fig. 1. «30 St Mary Axe» (179.8 m), London.

«30 St Mary Axe», better known under the name of «The Gherkin» or «Swiss Re» (see Fig. 1), a 40-storey tall building of a unique round shape in London, can serve as an example of «a public single function (office) tall building». This glass skyscraper is 179.8 meters (40 floors) high. It is the project of the architect Norman Foster. This is an entirely office building with a small restaurant and bar occupying the top 39 and 40th floors which is only small part of the total area of the building. It is open only for office staff working in the building. There are no service functions at the ground level [12].

"Greatwall Tower 1», an office complex in Wuhan, China, is can be described as «a single-function office complex with provision of services» (see Fig. 2). This complex consists of two towers with offices and a 4-storey podium which holds a shopping mall with elements of service, terraces for relaxing walks, an amphitheater, open and accessible to the public [13]. 

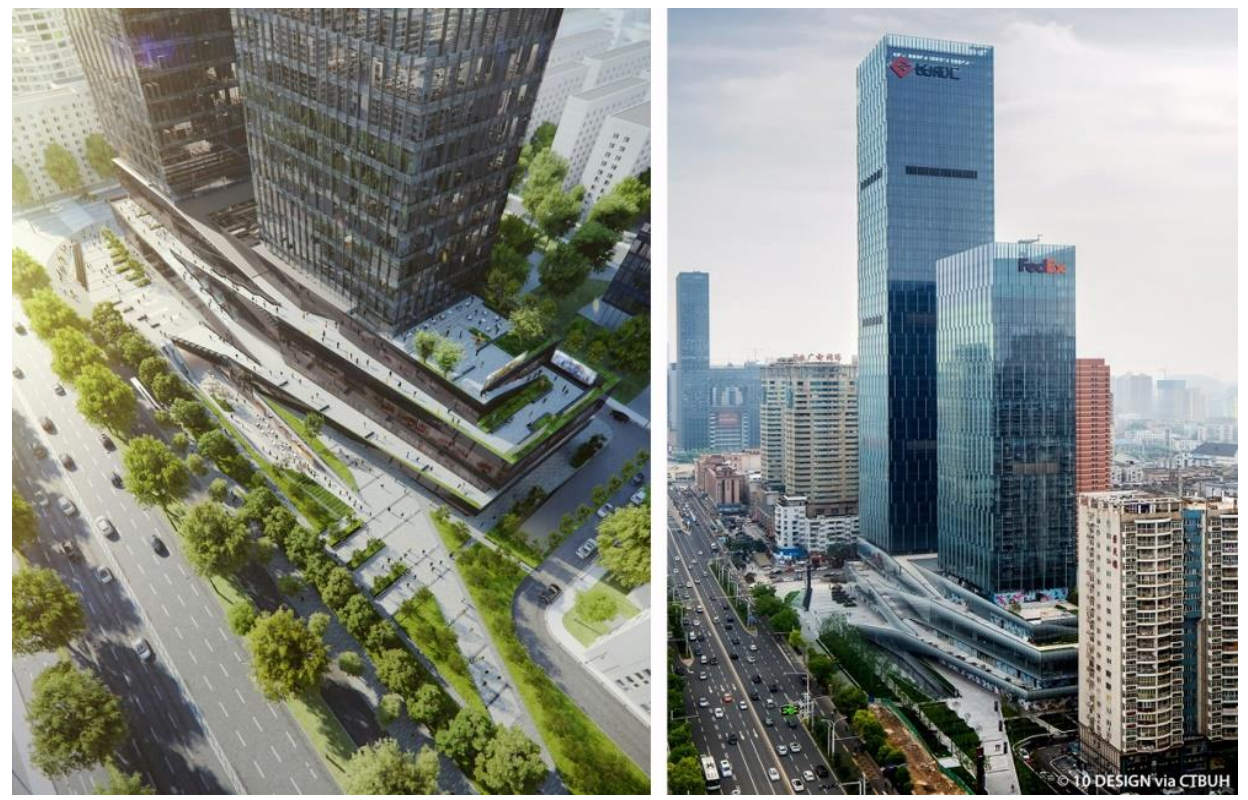

Fig. 2. «Greatwall Tower 1» (240.0 m), Wuhan (China) [http://skyscrapercenter.com/building/greatwall-tower-1/26388].

Jiangxi Nanchang Greenland Zifeng Tower in Nanchang, China, a 56-storey (268 meter) building, should be referred to «mixed-use tall buildings with provision of services». Two-thirds of the building is occupied by offices, and the upper, more prestigious floors, are occupied by a luxurious hotel occupies [14]. This building stands on the podium which houses service functions. There are open terraces, rest areas, etc. (see Fig. 3a) on its accessible roof.
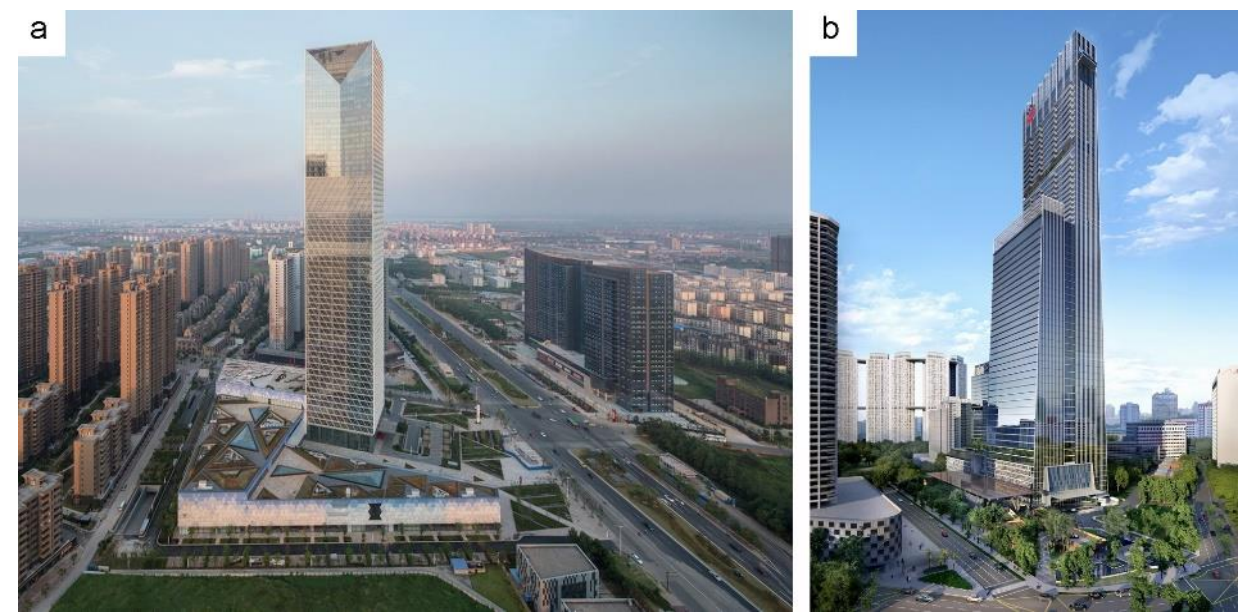

Fig. 3. Mixed-use tall buildings, a - «Jiangxi Nanchang Greenland Zifeng Tower» $(268.0 \mathrm{~m})$, Nanchang (China), b - «Tanjong Pagar Centre» (290.0 m), Singapore.

«Tanjong Pagar Centre», an unique skyscraper built in Singapore over the Central MRT station, can serve as a vivid example of «a mixed-use tall building with provision of services». MRT station provides easy access to any part of the city. There are office, residential and hotel functions in the structure of this building providing its multi- 
functionality [15]. Service functions, which are located in both the 6-storey podium and in a tall building bulk, include: restaurants, a conference center, a gym, a swimming pool, parking lots, and numerous shops (see Fig. 3b). Accommodation service facilities on the upper floors, stretching them vertically in the building is one of new trends in the typological diversity of tall buildings for various purposes. This technique makes it possible to bring service elements closer to working areas in office facilities or to living apartments [16].

«ICE Condominiums at York Centre», consisting of two residential tall buildings located on one podium, can be referred to «a single-function residential tall complex with provision of services». The complex is built in Toronto, Canada (see Fig. 4). The height of residential buildings is 234.1 and 202.3 meters, 67 and 57 floors, respectively. There are medical and sport facilities such as a gym with the latest cardio-training equipment, a swimming pool, leisure and entertainment zones, playgrounds for children, etc. in the structure of the podium $[17,18]$. The inclusion of service functions into the structure of the podium creates a comfortable modern living environment for residents of the complex.
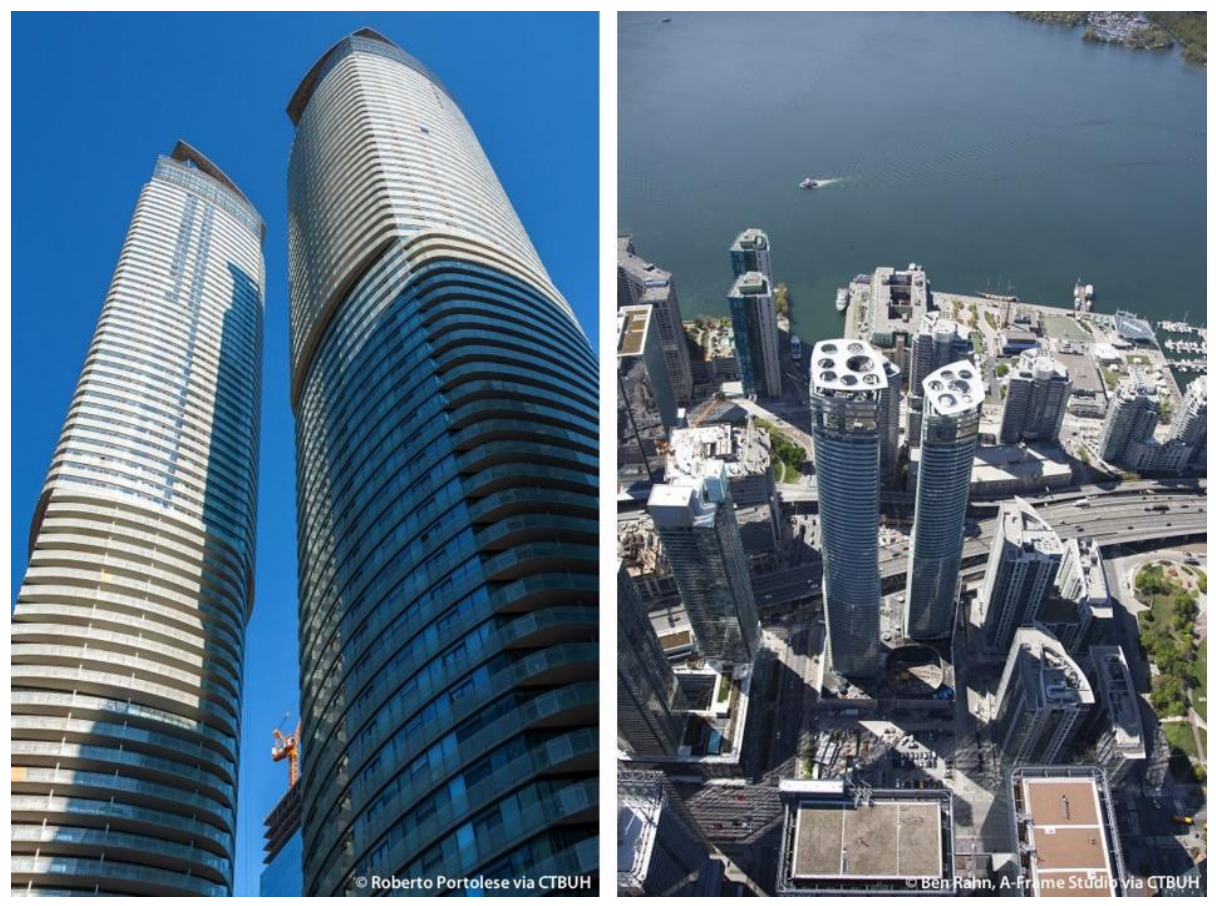

Fig. 4. «ICE Condominiums at York Centre $2 »(234.1 \mathrm{~m})$, Toronto (Canada)

[http://skyscrapercenter.com/building/ice-condominiums-at-york-centre-1/11636].

\section{Conclusions}

In conclusion, let us emphasize that at the moment there is still a search for more advanced types of tall buildings and complexes. New space-planning decision are introduced. There are also attempts to implement production functions into the structure of buildings. Besides, there are attempts to create a comfortable living environment while developing underground space and including service elements not only into the ground floor level, but also placing these functional zones in the vertical structure of tall buildings.

There is another conclusion based on the materials of CTBUH studies which were presented at international conferences held in New York and Shenzhen. According to these 
studies, the typology of tall buildings at the present stage reaches a new level of spaceplanning and functional structure. Currently, development constructors and architects of skyscrapers promote a new typology of a «3D», «multi-layer tall building» which will fundamentally change the urban vector frame. According to these developments, urban environment will be repeatedly «replicated» vertically in these tall complexes, which will include different functions, e.g. sports, leisure, educational, medical, health-giving, shopping facilities, etc.

The typological structure classifying tall buildings in relation to their functionalorganizing elements, introduced in this paper, makes it possible to introduce regulatory requirements both to separate tall buildings and to tall complexes, as well as to solve problems related to the regulatory framework in the design, construction and operation of tall buildings. The classification also provides conditions for type-design practice of tall buildings along with their sophisticated functional planning structures.

\section{References}

1. E. M. Generalova, V. P. Generalov, N. D. Potienko, Affordable housing under shaping dense vertical urbanism: Cities to Megacities: Shaping Dense Vertical Urbanism. Proceedings of the CTBUH. Council on Tall Buildings and Urban Habitat, 650-659 (Chicago, 2016)

2. V. P. Generalov, E. M. Generalova, Development Prospects for a typology of Hi-rise Buildings. The future of cities, Vestnik of SGUACE, Town Planning and Architecture, 1(18), 13-18 (2015) DOI: 10.17673/Vestnik.2015.01.2.

3. A. A. Kolosovskaya, N. D. Potienko, Evolution of the Typological Structure of Rental Accommodation Abroad, Town Planning and Architecture, 3(24), 109-115 (2016) DOI: 10.17673/Vestnik.2016.03.12.

4. V. P. Generalov, E. M. Generalova, Sustainable architecture. Energy Efficiency and Sustainability of Affordable Housing on the Example of Hong Kong, Vestnik of SGUACE. Town Planning and Architecture, 4(21), 23-29 (2015) DOI 10.17673/Vestnik.2015.04.3.

5. E. M. Generalova, V. P. Generalov, A. A. Kuznetsova, Modular Buildings in Modern Construction, Procedia Engineering, 153, 167-172 (2016)

6. A. Y. Zhigulina, Foreign and home experience in designing energy efficient residential houses, Vestnik SGASU, Town Planning and Architecture, 1, pp. 29-30 (2011)

7. A. Wood, Rethinking the Skyscraper in the Ecological Age: Design Principles for a New High-Rise Vernacular, Proceedings of the CTBUH Shanghai Conference «Future Cities: Towards Sustainable Vertical Urbanism», 26-38 (Shanghai, China, 16th-19th September 2014)

8. M. Balzannikov, V. Alpatov, I. Kholopov, A. Saharov, A. Lukin, Usage of spatial lattice metal structures as roofing for mechanical equipment rooms of hydroelectric power stations, MATEC Web of Conferences, 73, 01012 (2016).

9. A. O. Mateyko, Development History and Current Trends in High-rise Construction, Town Planning and Architecture, 3(24), 74-78 (2016) DOI: 10.17673/Vestnik.2016.03.12.

10. S. A. Kolesnikov, Town-Planning Principles of High-Urbanized Multi-Functional Units Formation of the largest city urban structure, Vestnik MGSU, 3, 25-29 (2009) 
11. T. Y. Vavilova, N. D. Potienko, I. V. Zhdanova, On Modernization of Capital Construction Projects in the Context of Sustainable Development of Social Sphere, Procedia Engineering, 153, 938-943 (2016)

12. http://archi.ru/projects/world/155/bashnya-30-st-mary-axe (last accessed Apr. 18, 2017)

13. https://skyscrapercenter.com/building/greatwall-tower-1/26388 (last accessed Apr. 20, 2017].

14. http://www.archello.com/en/project/jiangxi-nanchang-greenland-zifeng-tower (last accessed Apr. 20, 2017)

15. https://skyscrapercenter.com/singapore/guoco-tower/15186/ (last accessed Apr. 20, 2017)

16. V. P. Generalov, E. M. Generalova, High-Rise Complexes with Serving Zones of Vertical Configuration, Scientific Survey, 3, 163-167 (2015)

17. http://urbantoronto.ca/news/2015/05/\%C3\%AFce-condominiums-east-tower-nearingcompletion (last accessed Apr. 20, 2017)

18. http://www.skyscrapercenter.com/complex/172 (last accessed Apr. 20, 2017) 